\title{
Microgram Equivalent
}

National Cancer Institute

\section{Source}

National Cancer Institute. Microgram Equivalent. NCI Thesaurus. Code C105497.

A unit of relative amount of substance concentration equal to one millionth of a gram of an equivalent weight. 